\title{
¿Puede volver a caer el dólar?
}

Carlos José García T.

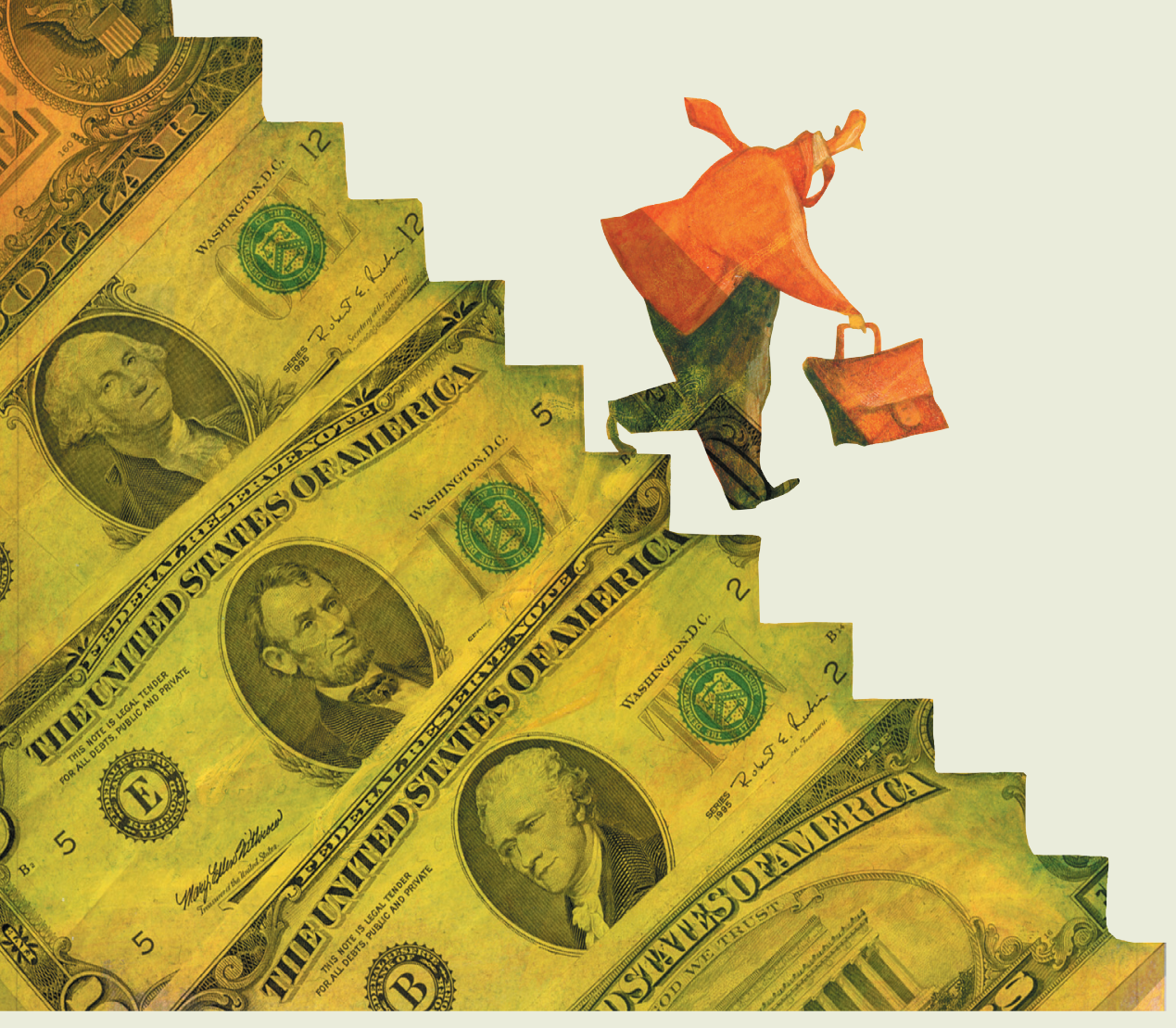

\section{Introducción}

El actual valor del dólar está en un equilibrio precario. Durante lo que resta de 2007 hay varios factores que pueden cambiar las expectativas de mercado empujando el valor del dólar por debajo de los niveles actuales. En el frente doméstico están las presiones inflacionarias: todo indica que pueden surgir sorpresas por este lado, especialmente por el dinamismo de la demanda agregada privada, que en parte está detrás del buen comportamiento observado de la economía durante el primer trimestre de 2007. En ese caso, el Banco Central puede verse obligado a adelantar subidas de tasas de interés y hacer caer aún más el dólar. Otro elemento es la relación entre el precio del cobre y el gasto fiscal. En la medida que los altos precios del cobre sean percibidos como más permanentes por los mercados, estos internalizarán que habrá más espacio para que el gobierno aumente su gasto y así genere presiones a la baja en el precio de la divisa. La relajación de la regla fiscal de $1 \%$ a $0,5 \%$ abre espacio para producir un efecto similar. De hecho, esta media fue anunciada en paralelo con el aviso de un aumento de los límites de inversión de las AFP en el extranjero. Por ahora este segundo efecto ha sido más fuerte. Sin embargo, en la medida que los mercados internalicen que el gasto de gobierno es esencialmente en bienes domésticos, puede haber nuevas presiones a la baja en el dólar. Hay factores externos que también colaboran con el aumento de la inestabilidad de los actuales niveles que se observan en el dólar; primero, el desempeño sistemáticamente mejor a lo esperado en las economías emergentes, lo que facilita el acceso de ellas a los mercados de capitales internacionales, a recursos abundantes y bajos spreads soberanos. Segundo, aún está latente la incertidumbre respecto al crecimiento de EE.UU., generando fluctuaciones en el valor final del dólar en los mercados internacionales.

Sin embargo, hay que ponderar en su justa medida el impacto del dólar en la economía chilena. El tipo de cambio real, la variable que define la evolución de las exportaciones, depende además de otras paridades (euro, yen, yuang, real, etc.). En la actual coyuntura internacional, las sorpresas en los mercados internacionales que pueden cambiar las expectativas de mercados están inclinadas hacia debilitar el dólar. Con todo, si el dólar cae en Chile es muy probable que también ocurra en otras economías, y que eso compense, en parte, el efecto final sobre el tipo de cambio real. Crítico será lo que suceda en el 


\section{Observatorio Económico}

frente interno, en especial lo que ocurra con la demanda agregada privada y la conducta de la política fiscal para administrar este nuevo escenario con abundancia de recursos provenientes del cobre.

\section{II. ¿Por qué puede caer el dólar?}

Parte de los malos resultados en proyectar el dólar como otras monedas es asignar ${ }^{1}$ excesiva importancia en su explicación a los fundamentos actuales de la economía. Existe relativo consenso sobre el hecho de que un análisis basado en los valores actuales de variables monetarias (precios, tasas de interés, flujo de capitales, precio del cobre, etc.) es relativamente poco útil a pesar de que se usa para contar historias congruentes pero difíciles de verificar empíricamente y, por tanto, de muy poca utilidad para los mercados y los agentes que deben tomar decisiones con esa información (exportadores, especuladores, autoridades, etc.). Por el contrario, evidencia reciente indica que los tipos de cambios (ejemplo peso/dólar) responderían más fuertemente a cambios en las expectativas de mercado ${ }^{2}$. Si bien éste no es un resultado nuevo, y está incorporado de alguna forma en el análisis de analistas y académicos, la ponderación que se da a las expectativas era más bien limitada. No obstante, hay elementos claves que se minimizan u omiten si las expectativas de mercado de escenarios futuros no son ponderadas en su justa medida.
Un ejemplo claro de esto son las expectativas privadas respecto de la política monetaria futura. El Banco Central de Chile, como otros bancos, ha optado por tener un régimen monetario de metas de inflación con tipo de cambio flexible. Por tanto, un aumento de la inflación no necesariamente produce un aumento del dólar estadounidense:puede ocurrir exactamente lo contrario. La reacción que ha tenido el Banco Central de Chile cuando la inflación sube sobre ciertos rangos es subir también la tasa de política monetaria (TPM) y esperar con esto una caída del dólar. El gráfico 1. A muestra la relación entre el precio del dólar y las expectativas privadas de la TPM a un año para el período 2000 - 2007 (obtenida de la encuesta de expectativas del Banco Central de Chile). Se puede notar que hay una relación negativa: expectativas de tasas altas están asociadas a un dólar más bajo. En otras palabras, si hay sorpresas negativas por el lado de la inflación, el mercado esperará un adelanto en los aumentos de la TPM, lo que causará una caída del dólar hoy. Éste es un escenario complicado para el dólar puesto que el Banco Central tendría menos espacio para intervenir verbal o activamente en ese mercado dada su prioridad en la inflación.

\section{Grafico 1}

Relación entre dólar y expectativas de fundamentales, 2000-2007
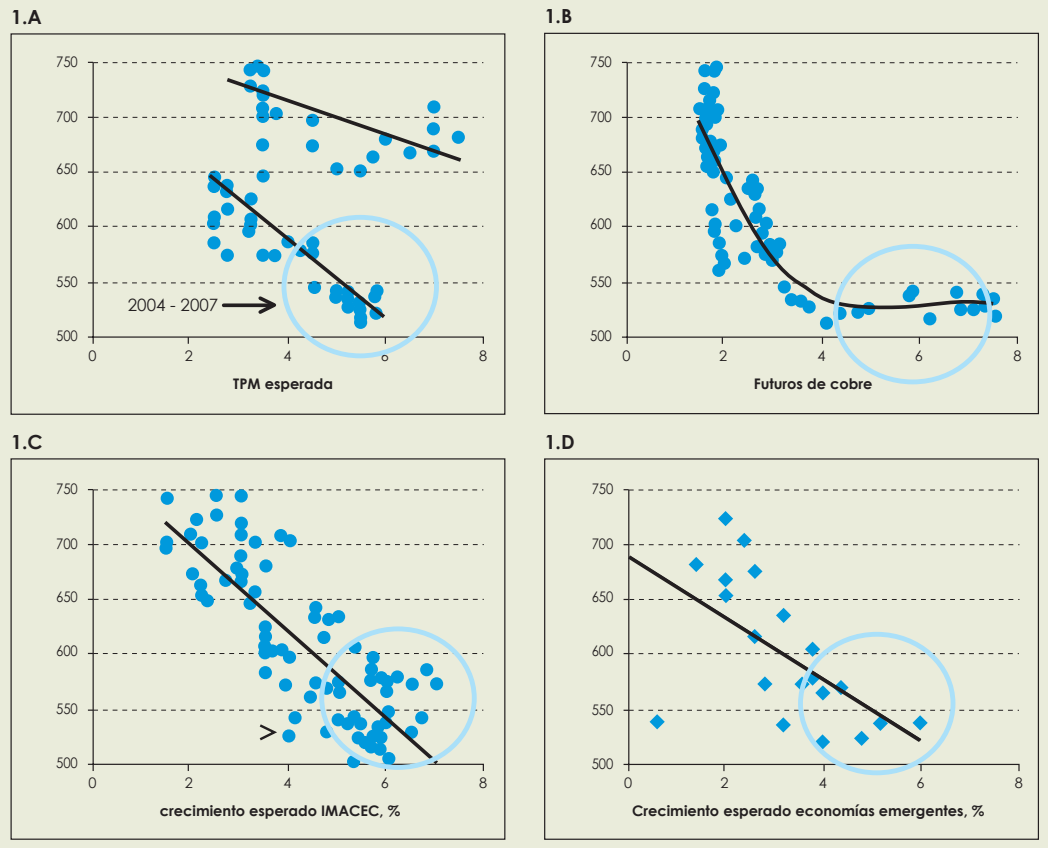

Fuente: BCCh y Bloomberg.

1 Meese, R. y K. Rogoff, 1983, Empirical Exchange Rate Models of the Seventies: Do They Fit Out of sample?, Journal of International Economics 14, 3-24.

2 Engel, C., N. Mark, y K. West, 2007, Exchange Rate Models are Not as Bad as You Think, preparado para NBER Macroeconomic s Annual 2007. 
En la medida que los altos precios del cobre sean percibidos como más permanentes por los mercados, estos internalizarán que habrá más espacio para que el gobierno aumente su gasto y así genere presiones a la baja en el precio de la divisa. La relajación de la regla fiscal de $1 \%$ a $0,5 \%$ abre espacio para producir un efecto similar

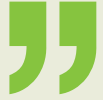

Otros elementos muy importantes son los ingresos del cobre y una mayor expansión del gasto fiscal. En efecto, desde hace algunos años el gobierno ha fijado como eje de su política fiscal la regla de superávit estructural, la cual implica que si el precio actual del cobre es más alto que el precio de largo plazo (establecido por un grupo de expertos), el gobierno ahorra eso recursos para postergar a través del tiempo su uso. En consecuencia, si las expectativas de mercado consideran esto, el precio del dólar no debiera responder en forma importante a un aumento actual en el precio del cobre. El gráfico 1.B muestra la relación entre el precio del dólar y los futuros de precio del cobre a un año, como una aproximación a las expectativas de mercado. Se observa que si bien hay una relación negativa entre estas dos variables, a medida que el precio de los futuros ha aumentado, alcanzando los niveles que se observan en la actualidad, el dólar se ha mantenido relativamente estable. Este un resultado que se puede esperar si efectivamente la regla de superávit estructural está operando y el mercado internaliza correctamente esa forma de hacer política fiscal. En otras palabras: precios demasiado altos no son percibidos como niveles sostenibles en el largo plazo, y por tanto no debieran ser considerados como ingresos estructurales y por ende no significarían ni mayor gasto público ni una caída del dólar. Así, los mayores precios del cobre van a significar una mayor apreciación sólo si estos son percibidos como permanentes. Detrás de esos factores están, entre otros, la demanda creciente de China y -ahorade India por materias primas. Sólo en la medida de que estos países mantengan su influencia en el mercado de commodities la percepción de los mercados podría cambiar afectando más decididamente el precio del dólar.

Un efecto adicional de la política fiscal es la relajación de la regla del superávit estructural de $1 \%$ a $0,5 \%$ anunciada el 21 de mayo y que será efectiva en 2008. Si bien esta noticia fue inicialmente más que compensada por el proyecto que elevará de un $30 \%$ a un $45 \%$ el límite de inversión en el extranjero para las AFP, hay que considerar un elemento adicional: todavía los mercados pueden no haber considerado completamente que el gasto de gobierno es esencialmente en bienes domésticos y en la medida que eso se materialice habrá presiones a la baja para el dólar.

Otros determinantes importantes que influyen en las expectativas del precio del dólar son las perspectivas sobre el propio crecimiento de la economía chilena. En la actual coyuntura, las expectativas de cre-

\section{EXCELENTES PROFESIONALES, grandes personas

\section{Estudia Ingeniería Comercial e Ingeniería Comercial para Profesionales}

Almirante Barroso N 6, Metro Los Héroes.

Teléfono:(56 2)6920200•admision@uahurtado.cl
UNIVERSIDAD ALBERTO HURTADO LA UNIVERSIDAD JESUITA DE CHILE
FACULTAD DE ECONOMIA Y NEGOCIOS 


\section{Observatorio Económico}

cimiento de nuestra economía son buenas, en especial respecto de otras economías como la de EE.UU. Se puede esperar un incremento no sólo de la demanda de bienes importados por mayor ingreso sino también de bienes no transables que presionen hacia un alza del peso. El cuadro 1.C muestra la relación entre las expectativas de crecimiento del IMACEC a un año y el dólar. Claramente se observa una relación negativa; más crecimiento esperado también significa un dólar más bajo. Las expectativas de mercado de la economía chilena también pueden ir en esa dirección para los próximos meses. En efecto, si los mercados reciben noticias cada vez mejores sobre la evolución de la economía, el dólar tenderá a caer más.

Por otro lado están las expectativas de los mercados financieros internacionales respecto del desempeño de las economías emergentes. En efecto, expectativas de mayor crecimiento en las economías emergentes también estarán asociadas a dos elementos dirigidos reducir el dólar: más flujos de capitales directos y menores spreads soberanos. Ambos efectos aumentan la oferta de dólares y presionan el precio a la baja. El cuadro 1.D relaciona el precio del dólar con las expectativas de crecimiento de economías emergentes a un año (Latinoamérica y Asia). Se observa que el mayor crecimiento esperado esta relacionado con un peso/dólar más bajo. Las expectativas para este año en general son buenas para las economías emergentes y estas pueden mejorar aún más de lo esperado durante el 2007.

Con todo, el valor actual del dólar esta en un equilibrio inestable. Las expectativas privadas de un conjunto de variables económicas claves pueden cambiar rápidamente en la coyuntura actual. En el frente interno están los riesgos de que la economía se sobrecaliente a una velocidad más rápida de lo esperado. Nuevos datos e información sobre el dinamismo de la demanda interna, la expansividad de la política fiscal y las expectativas sobre la mayor permanencia del precio del cobre a niveles altos pueden llevar el dólar por debajo de los niveles actuales. De hecho el anuncio de la baja del superávit estructural del 21 de mayo fue realizado en conjunto con el anuncio de un aumento de los límites de inversión en el extranjero para las AFP. Inicialmente se entendió como un aumento de los límites más rápido a los esperados pero luego ha sido aclarado que este será un proceso también gradual. A esto se suman las condiciones financieras internacionales cada vez más favorables para economías emergentes y la incertidumbre respecto a la evolución de la economía de EE.UU.

\section{Paridad peso/dólar y tipo de cambio real de Chile: parecidos a veces, pero diferentes}

No obstante el interés que concentra la evolución del dólar en la discusión pública, éste es sólo un parte de la historia (aunque importante) de los determinantes del comercio chileno. Las exportaciones dependen entre otras cosas del valor real del peso respecto de una canasta de monedas ponderadas por el comercio respectivo, que es el tipo de cambio real multilateral calculado por el Banco Central ${ }^{3}$. En el gráfico 2 se observa la relación entre este precio y las exportaciones de algunos productos no mineros claves del sector para el período 1996-2006: uva, productos industriales, vino y salmón. Como se puede observar, los volúmenes exportados en estos sectores han estado asociados positivamente con el tipo de cambio real.

Hay que ponderar en su justa medida el impacto del dólar en la economía chilena. El tipo de cambio real, la variable que define la evolución de las exportaciones, depende además de otras paridades (euro, yen, yuang, real, etc.). En la actual coyuntura internacional, las sorpresas en los mercados internacionales que pueden cambiar las expectativas de mercados están inclinadas hacia debilitar el dólar

Por otra parte, un grupo que siempre se deja de lado cuando se analiza el impacto del dólar es el de los consumidores, quienes se verían beneficiados por la importación de bienes más baratos. Sin em-

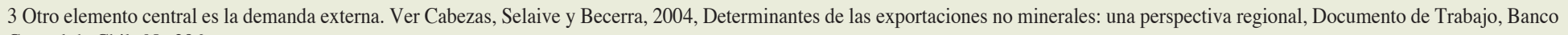
Central de Chile No 296. 
bargo, por algunas razones este efecto no es completamente directo por el traspaso imperfecto de tipo de cambio a precio. En efecto, desde los noventa los traspasos son lentos y por lo menos en el corto plazo, las fluctuaciones cambiarias explican más los cambios en los márgenes de los importadores que variaciones en el precio final de los consumidores.

La canasta de moneda que toma el tipo de cambio real para su construcción sugiere que también es importante seguir la evolución de otras paridades respecto al dólar como el euro, el yen, el real, el yuang y otros. Especialmente cuando en la actual coyuntura internacional se observa una importante disparidad en el crecimiento de nuestros socios comerciales. Por un lado se espera una desaceleración de EE. UU., en cambio Europa y Asia siguen creciendo a tasas más altas que las esperadas a comienzo de año. Analistas de mercado esperan que la economía de EE.UU. crez-

\section{Master of Arts in Economics}

\section{ILADES / GEORGETOWN UNIVERSITY}

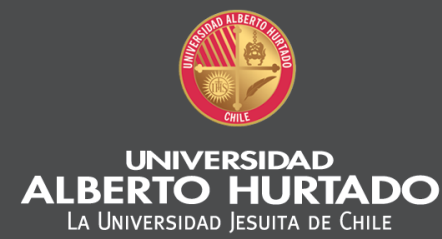

LA UNIVERsidad Jesuita DE ChILE

\section{GEORGETOWN UNIVERSITY}

\section{El Programa de Postgrado en Economía es conducente}

al grado académico de "Master of Arts in Economics" (MAE),

que otorga Georgetown University y al grado de Magíster

en Economía que otorga la Universidad Alberto Hurtado.

El programa presenta tres variantes:

- Programa General

- Programa con Mención en Políticas Sociales (Public Economics)

- Programa con Mención

en Economía de Empresas (Business Economics). ca por lo menos un punto menos en 2007. Las expectativas se han mantenido pero existe bastante incertidumbre respecto del ajuste del mercado inmobiliario y aún puede ser que esta economía sorprenda con un crecimiento aún menor e incluso con una recesión. También se proyecta un crecimiento para Europa de 2,4\% en 2007, cinco décimas más que lo esperado en enero de 2007. Las proyecciones para Japón en 2007 también se han corregido al alza y se espera un crecimiento de $2,2 \%$. Asia sigue creciendo, en especial China con una expansión esperada del PIB de $10,0 \%$ durante este año a pesar de los aumentos de la tasa de política monetaria del Banco Popular de China para desacelerar la economía.

Si hay sorpresas negativas por el lado de la inflación, el mercado esperará un adelanto en los aumentos de la TPM, lo que causará una caída del dólar hoy. Éste es un escenario complicado para el dólar puesto que el Banco Central tendría menos espacio para intervenir verbal 0 activamente en ese mercado dado que su prioridad está en la inflación 


\section{Observatorio Económico}

\section{Gráfico 2}

Relación entre Exportaciones de Productos no Minerales y Tipo de Cambio Real (1996-2006)
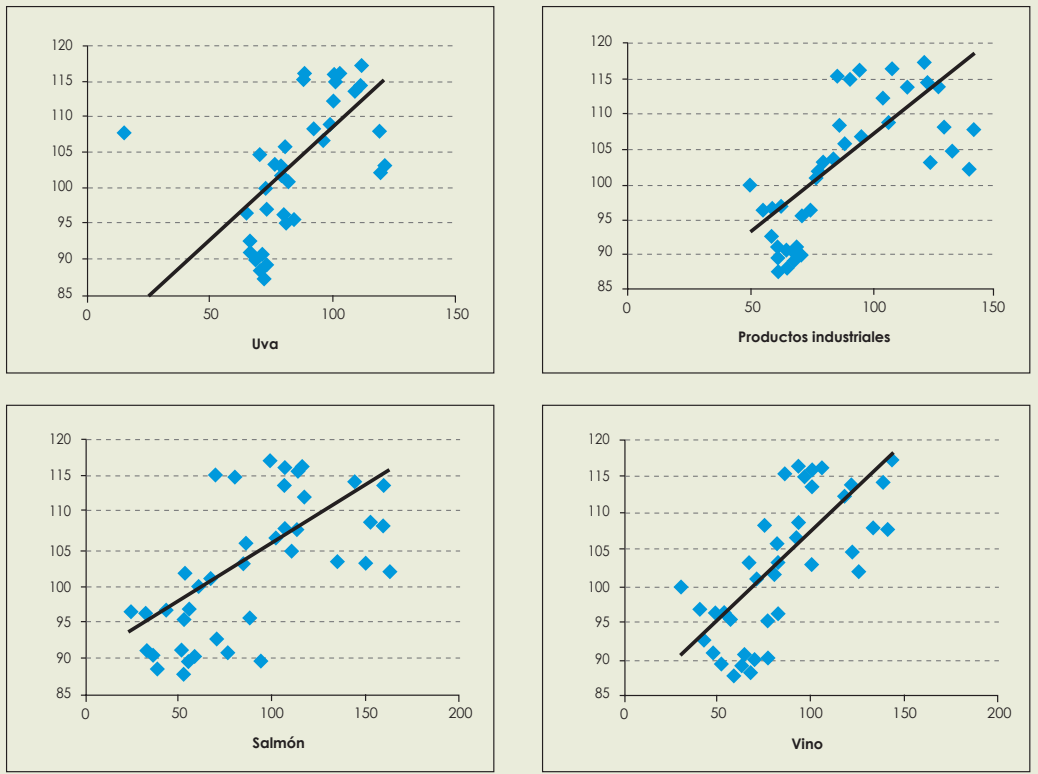

Fuente: BCCh

\section{Gráfico 3}

Paridades y Tipo de Cambio Real, 1999-2007
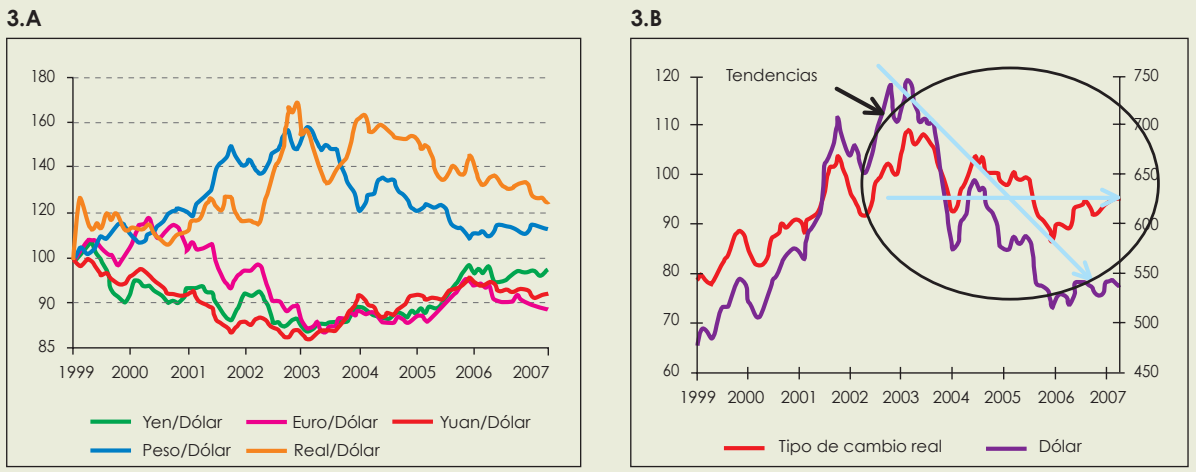

Fuente: BCCh

Todos los elementos anteriores apuntan a una depreciación del dólar estadounidense durante este año. Como se observa en el gráfico 3.A, el Euro y Yuang se han apreciado. El Yen se ha depreciado pero esto es producto de las operaciones de carry trade que los inversionistas realizan ha venido ocurriendo desde mediados del año pasado. Como resultado, si uno compara el tipo de cambio real de Chile con la paridad peso/dólar (Gráfico 3.B), se tiene que la apreciación del peso con respecto al dólar no se ha reflejado completamente en una caída del tipo de cambio real porque importantes monedas también se han apreciado.

Por otra parte, un grupo que siempre se deja de lado cuando se analiza el impacto del dólar es el de los consumidores, quienes se verían beneficiados por la importación de bienes más baratos. Sin embargo, por algunas razones este efecto no es completamente directo por el traspaso imperfecto de tipo de cambio a precio. En efecto, desde los noventa los traspasos son lentos...

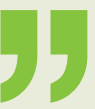

Las expectativas de mediano plazo también podrían ir en la dirección de una mayor depreciación del dólar estadounidense en los mercados internacionales. Efectivamente, EE.UU. mantiene un déficit de cuenta corriente cercana al 1,5\% del PIB mundial. En el caso de que la economía 
de EE.UU. deba cerrar dicho déficit, situación que no es evidente y que es tema de debate entre economistas, el dólar debe depreciarse para hacer más competitivas las exportaciones de EE.UU. y ajustar las importaciones, especialmente los productos provenientes desde Asia, en particular de China. El tema de los desbalances globales, el déficit de EE.UU. con el correspondiente superávit en otras economías, es todavía un muy incierto y puede ser generador de noticias inesperadas sobre las expectativas de mercado que afecten el dólar, especialmente si consideramos que existe incertidumbre sobre la evolución futura de la economía de EE.UU.

Otro elemento que suaviza el impacto de la apreciación de la paridad peso/dólar es la diversificación del comercio de Chile. En la tabla 1 se presenta la participación del comercio exterior (exportaciones más importaciones) de Chile desde 1990 por principales áreas geográficas. Podemos observar que si bien el comercio con EE.UU. sigue siendo importante, éste ha descendido hasta alcanzar un 15\% del total del comercio. Por otro lado, Europa y
Asia contabilizan alrededor del $50 \%$ del comercio de Chile; hay un marcado cambio de composición hacia Asia. Esto se explica por la evolución del comercio con China: en 2000 correspondía al 5,3\%, en 2006 alcanzaba el 9,0\%. Así el comercio de Chile se ha diversificado en el tiempo hacia regiones geográficas muy dinámicas y, por cierto, diferentes de EE.UU, lo que hace cada vez más relevante entender las fluctuaciones de las paridades del peso con otras monedas diferentes del dólar para entender la dinámica del comercio chileno.

\section{Conclusiones}

Estimamos que el actual valor del dólar esta en un equilibrio precario. Existen varios factores que pueden empujar esta moneda por debajo de los niveles actuales. Detectamos al menos cinco frentes que pueden cambiar las expectativas de mercado y llevar el valor de la divisa por debajo de ese piso, más bien psicológico que real. En el frente doméstico están las presiones inflacionarias, como el propio Banco Central reconoce en su Informe de

\section{Tabla 1}

Participación del Comercio Exterior de Chile por Áreas Geográficas, (\% sobre el total de comercio, exportaciones+importaciones)

\begin{tabular}{l|ccc}
\multicolumn{1}{c}{} & $\mathbf{1 9 9 0}$ & $\mathbf{2 0 0 0}$ & $\mathbf{2 0 0 6}$ \\
\cline { 2 - 4 } Estados Unidos & 17,5 & 17,9 & 15,3 \\
Mercosur & 10,8 & 16,5 & 13,2 \\
Unión Europea & 32,1 & 20,3 & 21,5 \\
Asia & 20,0 & 23,6 & 28,9
\end{tabular}

Fuente: BCCh

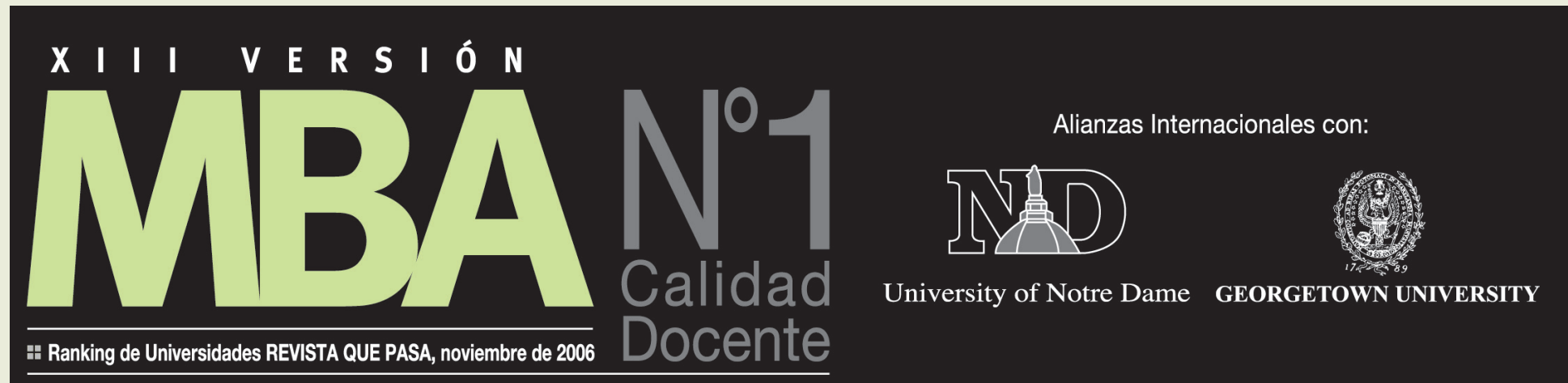

INICIO DE CLASES

20 de abril - Clases viernes y sábados cada tres semanas Almirante Barroso N ${ }^{\circ}$, Los Héroes mba@uahurtado.cl • www.uahurtado.cl/mba
UNIVERSIDAD

ALBERTO HURTADO LA UNIVERSIDAD IESUITA DE CHILE
FACULTAD DE

ECONOMÍA

Y NECOCIOS 


\section{Observatorio Económico}

Política Monetaria (IPoM) de mayo 2007. Nada dice que no sigan surgiendo sorpresas en este frente, especialmente por el dinamismo de la demanda agregada, que en parte está detrás del buen desempeño de la economía durante el primer trimestre de 2007. Es así como las expectativas de crecimiento se han ajustado al alza durante todo estos meses.

Por otra parte, el dólar puede caer más en la medida que los altos precios del cobre sean percibidos por el mercado como más permanentes y, por tanto, sinónimo de más gasto fiscal futuro. Un efecto adicional de la política fiscal es la relajación de la regla del superávit estructural de $1 \%$ a $0,5 \%$ anunciada el 21 de mayo y que será efectiva en 2008. De hecho, el anuncio fue realizado en conjunto con el aviso de un aumento de los límites de inversión en el extranjero para las AFP. Por ahora el segundo efecto ha sido más fuerte, no obstante en la medida que los mercados internalicen que el gasto de gobierno es esen- cialmente en bienes domésticos y que el proceso de apertura para las AFP sea más gradual que los esperado, pueden haber nuevas presiones a la baja para el dólar.

Factores externos también colaboran en aumentar la inestabilidad de los actuales niveles que se observan en el dólar. Primero: el desempeño sistemáticamente mejor a lo esperado de las economías emergentes, lo que facilita el acceso de esas economías a los mercados de capitales internacionales. Segundo: aún existen incertidumbres respecto de la evolución futura del crecimiento en EE.UU., introduciendo volatilidad en el valor del dólar en los mercados internacionales.

Sin embargo, hay que ponderar en su justa medida el impacto del dólar en la economía chilena. El tipo de cambio real, medido por el valor real del peso respecto de una canasta de monedas y la cual si está relacionado directamente a la evolución del comercio, depende además de otras

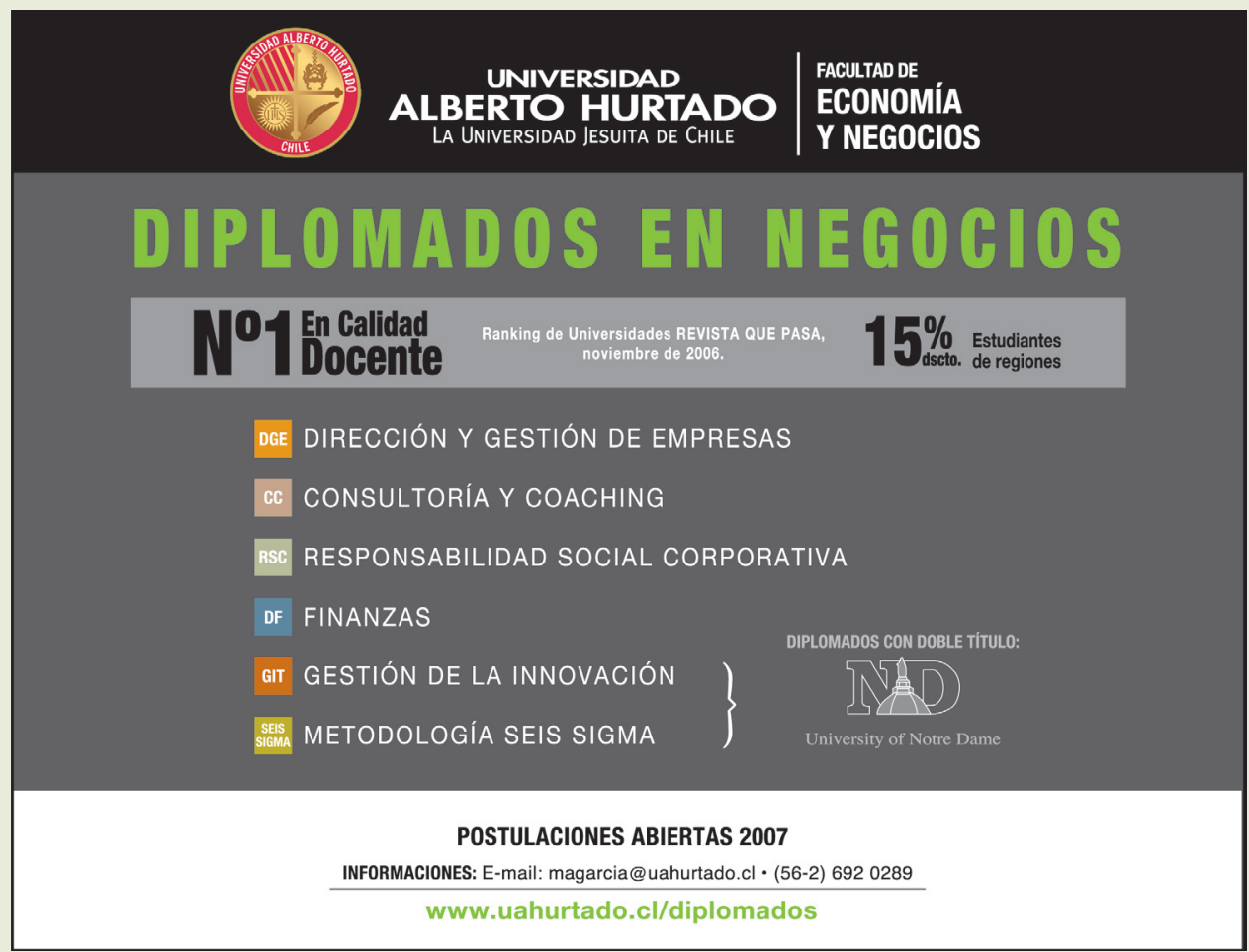

paridades. Las sorpresas en el frente externo que pueden cambiar las expectativas de mercado están inclinadas a debilitar el precio del dólar. Con todo, si el dólar cae en Chile, es también probable que ocurra en otras economías, compensando en parte el efecto sobre el tipo de cambio real.

El comercio de Chile se ha diversificado en el tiempo hacia regiones geográficas muy dinámicas $\mathbf{y}$, por cierto, diferentes de EE.UU, lo que hace cada vez más relevante entender las fluctuaciones de las paridades del peso con otras monedas diferentes del dólar para entender la dinámica del comercio chileno

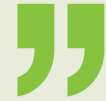

Será determinante lo que ocurra en el frente interno, en especial la evolución de la demanda agregada privada y la conducta de la política fiscal. Estos elementos pueden desbalancear las presiones hacia la baja en el tipo de cambio real en la medida que el Banco Central deba adelantar aumentos de tasas. Este puede ser un escenario complejo para el dólar, puesto que el Banco Central estará más restringido para intervenir, verbal o explícitamente, este mercado: su prioridad estará puesta en la inflación. 